\title{
A Novel Polymorphism of VLDLR Signal Peptide Coding Region and Its Association with Growth and Abdominal Fat Traits of Gaoyou Domestic Ducks
}

\section{-Author(s)}

\section{Ming-liang C \\ Cong $W^{\prime}$ \\ Xuan $D^{\prime}$ \\ Lu L' \\ Tang-jie Z}

College of Veterinary Medicine, Yangzhou University, Yangzhou 225009, China

\section{ABSTRACT}

The VLDLR gene plays important roles in the growth and adiposity in humans and mice. The purpose of this study was to investigate the relationship between $V L D L R$ gene genetic polymorphisms and growth and abdominal fat traits of the Gaoyou domestic duck. A total of 267 Gaoyou ducks were employed for testing. A 18bp deletion was identified in VLDLR signal peptide coding region. The results of $\chi^{2}$ test suggested that the genotype frequencies of VLDLR signal peptide coding region were not in Hardy-Weinberg equilibrium. Least squares analysis showed that body weight (BW) of $-18 \mathrm{bp} /-18 \mathrm{bp}$ genotype ducks was significantly higher than those of other genotypes from six (BW6) $(p<0.05)$ to ten weeks of age (BW10) $(p<0.01)$. The association analysis was performed taken body weight as covariant for abdominal percentage (AFP). Results showed that there was not interaction between genotype $(p>0.05)$ and body weight for AFP and different genotypes had a significant effect on AFP $(p<0.05)$. The results of Bonferroni t-test revealed that the abdominal fat percentage (AFP) of $-18 \mathrm{bp} /-18 \mathrm{bp}$ genotype was significantly lower than those of $+18 \mathrm{bp} /-$ 18bp $(p<0.05)$. Preliminary studies have shown that $V L D L R$ may be a candidate gene for the selection for growth and abdominal fat, and the results of the present study indicate that VLDLR strongly influences carcass abdominal fat content of Gaoyou ducks.

\section{INTRODUCTION}

Zhang Tang-jie

College of Veterinary Medicine, Yangzhou University, Jiangsu Yangzhou 225009,

China - 13013709846

Tel: $\quad$ +86051487979044

Email: slx@yzu.edu.cn

\section{EKeywords}

Polymorphism, VLDLR, abdominal fat trait, growth, duck.
Submitted: 24/March/2017

Approved: 14/June/2017
The very-low-density-lipoprotein receptor $(V L D L R)$ is a transmembrane lipoprotein receptor of the low-density-lipoprotein (LDL) receptor family. $V L D L R$ is widely distributed throughout the tissues of the body, including the skeletal muscle, adipose tissue, heart, and the brain, but it is absent from the liver (Nimpf \& Schneider, 2000). The VLDLR also exhibits high homology among various species, of up to $95 \%$ among rats, mice, rabbits, and humans. There is approximately $84 \%$ conservation with the respective protein in chickens (Nimpf \& Schneider, 1998; Nimpf \& Schneider, 2000).

$V L D L R$ is a peripheral lipoprotein receptor that primarily modulates the extra-hepatic metabolism of triglyceride-rich lipoproteins and acts on cardiac fatty acid metabolism, lipoprotein metabolism, and fat deposition (Yagyu et al., 2002). In addition, VLDLR allows fatty acids to enter the cells, where they are used as an energy source and to regulate the reelin signaling pathway (Takahashi et al., 1995; Tao et al., 2010). The duck VLDLR gene was cloned and characterized by Wang et al. (2011). The deduced amino acid sequence predicts a mature protein of 851 amino acids preceded by a 36-residue signal peptide.

Five structural domains of LDL receptor family are highly conserved: an extracellular N-terminal ligand-binding domain with cysteine-rich 
repeats, an O-linked glycosylation sugar domain, an epidermal growth factor (EGF), a single transmembrane sequence, and a cytoplasmic domain which contains an NPXY sequence. The NPXY motif functions in signal transduction and aggregation of receptors to coated pits (Reddy et al., 2011). It consists of the sequence Asparagine-Proline-X-Tyrosine, where $X$ can be any amino acid. According to reports, the VLDLR-null $\left(v / d / r^{\prime-}\right)$ mice are leaner, but have normal blood lipids (Frykman et al., 1995). In addition, since the absence of VLDLR leads to non-obesity in mice, it is assumed that this gene is associated with obesity (Goudriaan et al., 2001). The same principle applies to humans: those with VLDLR gene mutations have lower body weight compared with the control group (Boycott et al., 2005; Crawford et al., 2008). Therefore, VLDLR were confirmed to be associated with body weight and obesity in humans and mice (Brockmann et al., 1998; Kunej et al., 2012; Clemente-Postigo et al., 2011). In overweight humans, it was observed that VLDLR were significantly upregulated and their expression levels were probably closely linked to the molecular markers of obesity phenotype (Kim et al., 2012).

Growth rate and lean meat content (or low-fat deposition) are two commercially important indicators of poultry meat quality. The growth performance and carcass yield of the Gaoyou duck, a Chinese native breed in China, are inferior than those of meattype breeds, such as the Cherry Valley duck and the Muscovy duck, although it presents superior meat quality. Consequently, commercial breeders proposed breeding programs to select ducks with high growth rate and low carcass fat percentage. Genetic markers, which were linked to loci influencing traits like growth, can be exploited to improve the growth rate and the efficiency of duck breeding programs. Once a DNA polymorphism is found to be associated with a certain trait, that polymorphism can be considered as a candidate genetic marker for marker-assisted selection (MAS) programs.

Based on the observations in humans and mice, the $V L D L R$ gene may be considered as an important candidate gene for fat deposition traits, and may affect carcass and fat traits. Our previous study indicated that the VLDLR gene may be associated with abdominal fat in duck (Zhao et al., 2015). The objectives of the present study were to detect different polymorphic sites and investigate its association with growth and carcass traits of Gaoyou ducks, and to conduct further research on the possibility of using $V L D L R$ gene as molecular genetic markers for growth and main carcass traits (abdominal fat percentage - AFP, eviscerated weight percentage - EWP).

\section{MATERIALS AND METHODS}

\section{Sample collection and preparation}

A total of 280 hatching eggs were obtained from the elite reservation farm of Jiangsu Gaoyou duck company in Jiangsu province, China. All ducks were raised in floor pens under the same standardized management conditions, fed commercial corn-soybean diets that met the requirements of the NRC (1994).

Blood samples and phenotypic data on growth and carcass traits (hatchling weight, weekly body weight (BW) between 3 and 10 weeks of age, whole carcass weight $(\mathrm{CW})$, eviscerated carcass weight, and abdominal fat weight (AFW) of 267 individuals were determined. Birds were slaughtered using appropriate humane methods at 10 weeks of age after $6 \mathrm{~h}$ with no access to feed prior to transporting the ducks for slaughter processing.

Eviscerated carcass weight was determined as chilled carcass weight after the removal of feathers, lungs, heart, liver, gastrointestinal tract, kidneys, and abdominal fat. Carcass yield (CY), eviscerated carcass yield (ECY), and abdominal fat percentage (AFP) [AFP: $($ AFW /BW $) \times 100]$ were calculated as the ratio of these traits to body weight at 10 weeks of age (BW10). In this study, intramuscular fat and subcutaneous were not measured owing to experimental limitations.

Genomic DNA was obtained by phenol and chloroform $(1: 1)$ extraction, and stored at $-80^{\circ} \mathrm{C}$.

\section{Primer design, PCR amplification and identification of gene polymorphism}

The VLDLR genomic sequence (NM_001310401) was obtained from the National Center for Biotechnology Information (NCBI). One pair of primers (5'- ATTACACTGCCAAATGACC $-3^{\prime}$ and 5'- CGGGAACTGGGATTCTTC -3') was designed to amplify the duck $V L D L R$ gene signal peptide region. The product size was $374 \mathrm{bp}$.

Polymerase chain reaction (PCR) was performed using 50 ng DNA templates, $10 \mathrm{pM}$ of each primer, $0.20 \mathrm{mM}$ dNTP, $2.5 \mathrm{mM} \mathrm{MgCl} 2$ and $0.5 \mathrm{U}$ Taq DNA polymerase. Thermal cycling began with an initial denaturation step of $94^{\circ} \mathrm{C}$ for $10 \mathrm{~min}$, followed by 35 cycles of $94^{\circ} \mathrm{C}$ for $30 \mathrm{~s}, 53.5^{\circ} \mathrm{C}$ annealing for $30 \mathrm{~s}, 72$ ${ }^{\circ} \mathrm{C}$ for $30 \mathrm{~s}$, and concluded with a final extension at 72 ${ }^{\circ} \mathrm{C}$ for $10 \mathrm{~min}$. DNA sequencing was performed using an ABI 3130 Genetic Analyzer (Applied Biosystems, 
Ming-liang C, Cong W, Xuan D, Lu L, Tang-jie Z
A Novel Polymorphism of VLDLR Signal Peptide Coding Region and Its Association with Growth and Abdominal Fat Traits of Gaoyou Domestic Ducks
USA). Sequencing variants were detected by visual examination of the sequencing map followed by alignment using DNAMAN.

\section{Statistical analysis}

Genotype and allelic frequencies, genotypic numbers, effective allele numbers $(\mathrm{Ne})$ and gene heterozygosity $(\mathrm{He})$, polymorphism information content (PIC) were calculated, and their Hardy-Weinberg equilibrium was analyzed using the Chi-square test of the PopGene32 software (version 1.31).

The association of $V L D L R$ gene genotypes with growth and carcass traits, including hatchling weight, BW at weeks 3 to 10, carcass weight, eviscerated carcass weight, abdominal fat weight, carcass yield, and eviscerated carcass yield data were subjected to two-way analysis of variance using the SPSS software (version 16.0), using the following model: $Y=\mu+G+L+$ $G \times L+e$, where $Y$ is the dependent variable (analyzed traits), $\mu$ is the overall mean, $G$ is the genotype of different variations of the VLDLR gene, $L$ is the duck population, $G \times L$ is the interaction between genotype and duck population (fixed effect), and e is the random error. Genotype association analyses were performed using body weight as covariant for AFP. Differences among genotypes were determined by the least square and Bonferroni tests. Significance was assumed at $p<0.05$.

\section{RESULTS}

\section{Polymorphism detection}

identification

and

The sequences amplified with one pair of primer were aligned among Gaoyou ducks. A novel 18bp deletion in VLDLR signal peptide coding region at the nucleotide position 278-295bp was detected, resulting in three genotypes $(+18 \mathrm{bp} /+18 \mathrm{bp},+18 \mathrm{bp} /-18 \mathrm{bp}$ and$18 \mathrm{bp} /-18 \mathrm{bp})$. The sequences presenting variation in signal peptide coding region were submitted to GenBank (accession number: KU317918 for +18bp/+18bp allele and KU317919 for +18bp/-18bp allele).

As shown in Fig. 1 and Fig. 2, a 18bp deletion at locus 278-295 expressed three genotypes: $+18 \mathrm{bp} /+18 \mathrm{bp},+18 \mathrm{bp} /-18 \mathrm{bp}$ and $-18 \mathrm{bp} /-18 \mathrm{bp}$. The +18bp/+18bp genotype contains two +18bp single strands (allele $+18 \mathrm{bp}$ ); the $-18 \mathrm{bp} /-18 \mathrm{bp}$ genotype lack two $-18 \mathrm{bp}$ single strands (allele $-18 \mathrm{bp}$ ); the $+18 \mathrm{bp} /-$ $18 \mathrm{bp}$ genotype contains one 18bp single strand and one missed18bp single strand.

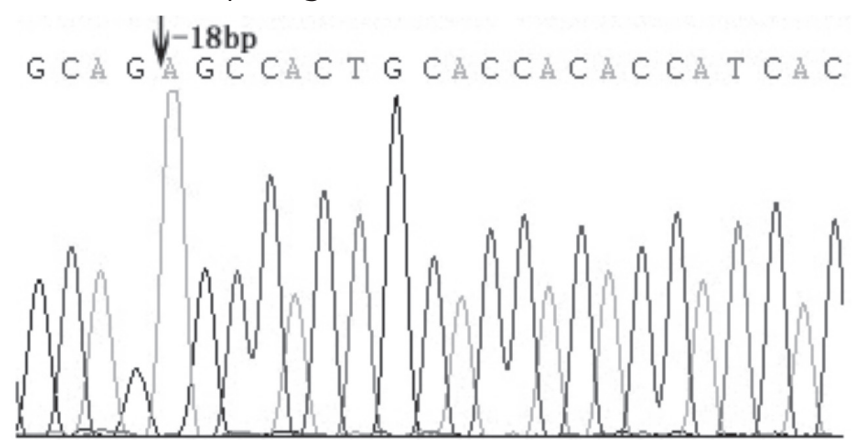

Figure 1 - Sequences amplified by primer signal peptide lackding two -18bp single strands

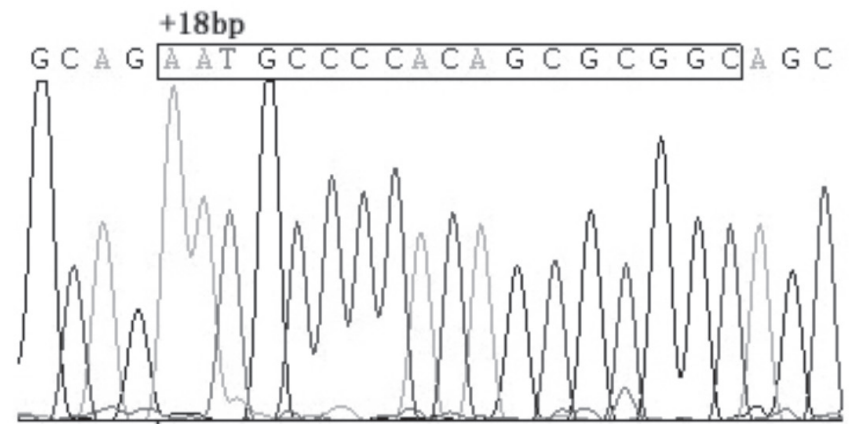

Figure $\mathbf{2}$ - Sequences amplified by primer signal peptide containing two $+18 \mathrm{bp}$ single strands

\section{Allele and genotype distribution of the $V L D L R$ gene signal peptide}

Allele and genotype frequencies found at the signal peptide (Table 1) indicated that the frequency of the genotype $+18 \mathrm{bp} /+18 \mathrm{bp}$ was higher than those of the $+18 \mathrm{bp} /-18 \mathrm{bp}$ and $-18 \mathrm{bp} /-18 \mathrm{bp}$ genotypes. The $+18 \mathrm{bp}$ allele frequency (0.70) was also much higher compared with -18bp which showed a high prevalence in the evaluated Gaoyou duck population. The Chisquare tests showed that the genotypic frequencies were not in Hardy-Weinberg equilibrium $(p<0.05)$. The values of the population genetic indices $(\mathrm{He}, \mathrm{Ne}$, and PIC) to evaluate the diversity of the population are also presented in Table 1 . The value of He (gene heterozygosity) was above 0.4 and below 0.5 , whereas values of $\mathrm{Ne}$ (effective allele numbers) approached 2 . The PIC values were 0.33.

Table 1 - Allele and genotype frequencies at the $V L D L R$ gene signal peptide region in Gaoyou duck populations ( $\mathrm{n}=267)$.

\begin{tabular}{|c|c|c|c|c|c|c|c|c|c|}
\hline \multirow{2}{*}{$\begin{array}{l}\text { Genotype } \\
+18 \mathrm{bp} /+18 \mathrm{bp}\end{array}$} & \multirow[b]{2}{*}{$+18 b p /-18 b p$} & & \multicolumn{2}{|c|}{ Allele } & \multirow{2}{*}{$\mathrm{He}$} & \multirow{2}{*}{$\mathrm{Ne}$} & \multirow{2}{*}{$\mathrm{PIC}$} & \multirow{2}{*}{$x^{2}$} & \multirow{2}{*}{ HWE } \\
\hline & & $-18 b p /-18 b p$ & $+18 \mathrm{bp}$ & $-18 b p$ & & & & & \\
\hline $0.65 / 174$ & $0.11 / 29$ & $0.24 / 64$ & 0.70 & 0.30 & 0.42 & 1.71 & 0.33 & 145.56 & $\mathrm{~N} / \mathrm{A}$ \\
\hline
\end{tabular}

$\chi_{0.05}^{2}(\mathrm{df}=1)=3.841, \chi_{0.01}^{2}(\mathrm{df}=1)=6.635$ 


\section{Association of polymorphism at $V L D L R$ gene signal peptide with growth and carcass traits}

The results of association analysis between different genotypes and growth and carcass traits are given in Table 2. The table shows no significant differences in hatchling weight, or in BW at 3, 4, and 5 weeks of age in the three genotypes, as determined by the least squares. However, the genotype-18bp/-18bp presented significantly higher BW at $6(p<0.05), 7(p<0.01), 8$ $(p<0.01), 9(p<0.01)$, and $10(p<0.01)$ weeks of age compared with the genotypes $+18 \mathrm{bp} /+18 \mathrm{bp}$ and $+18 \mathrm{bp} /-18 \mathrm{bp}$.

The covariate association analysis results showed that there was not interaction between genotype $(F=0.927$, $p=0.400)$ and body weight, and that genotype had a significant effect on AFP $(F=6.713, p=0.002)$. The results of Bonferroni t-test revealed that the ducks of the $-18 \mathrm{bp} /-18 \mathrm{bp}$ genotype presented significantly lower abdominal fat percentage compared with those of the genotype $+18 \mathrm{bp} /-18 \mathrm{bp}(p<0.05)$. Furthermore, no significant association among different genotypes with other traits (carcass yield and eviscerated carcass yield) was detected ( $p>0.05$ ).

\section{DISCUSSION}

The allele frequencies showed that the deletion of the 18 bases was polymorphic. The fact that Gaoyou duck population deviated from Hardy-Weinberg equilibrium $(p<0.05)$ may be due to the small sample size and long-term artificial selection for commercial purposes (such as growth, egg production, carcass weight). In selected populations, loci are expected to experience genotypic frequency deviation from the Hardy-Weinberg equilibrium, and that impact traits of the species under selection (Goliasova \& Wolf, 2004; Wu et al., 2012; Ismoyowati \& Purwantini, 2010).

According to the classification of PIC values $(\mathrm{PIC}<0.25$ $=$ low polymorphism; $0.25<\mathrm{PIC}<0.50=$ intermediate polymorphism; $\mathrm{PIC}>0.50=$ high polymorphism), the Gaoyou duck population presented intermediate levels of genetic diversity, suggesting that there is sufficient genetic diversity to allow its artificial selection for the improvement of growth, egg traits, etc.

Abdominal and subcutaneous fat are regarded as the main sources of waste in the processing plant. The results of Table 2 indicate that the VLDLR gene may be a candidate gene for the selection for higher growth rate and lower fat deposition, taking into account the high genetic correlations between abdominal fat weight and subcutaneous fat, while there are almost no genetic correlations between abdominal fat weight and intramuscular fat percentage (Zerehdaran et al., 2004; Lotfi et al., 2011) in poultry. This would be advantageous for human health. The VLDLR gene was associated with fatness traits, like AFP, in ducks, which is consistent with some studies in humans. Many studies have shown associations of VLDLR gene mutations with adiposity and body weight in humans, as previously mentioned in this paper. In a previous study (Zhao et al., 2015), we identified eight SNPs in the homologous domain of VLDLR EGF precursor and showed that there was a significant association between the VLDLR EGF precursor homologous domain and abdominal fat percentage (AFP) in ducks. Similar results were obtained in the present study by analyzing the polymorphism of signal peptide regions. Our findings further support that

Table 2 - Effects of polymorphism of the VLDLR gene signal peptide on duck growth and carcass traits $(n=267)$

\begin{tabular}{lccc}
\hline \multirow{2}{*}{ Trait } & \multicolumn{3}{c}{ Genotype } \\
\cline { 2 - 4 } & $+18 \mathrm{bp} /+18 \mathrm{bp}(\mathrm{n}=174)$ & $+18 \mathrm{bp} /-18 \mathrm{bp}(29)$ & $-18 \mathrm{bp} /-18 \mathrm{bp}(64)$ \\
\hline Hatchling weight & $47.49 \pm 0.50$ & $47.23 \pm 1.33$ & $48.46 \pm 0.74$ \\
BW 3 weeks & $610.77 \pm 11.00$ & $643.85 \pm 14.86$ & $622.21 \pm 16.35$ \\
BW 4 weeks & $855.40 \pm 18.67$ & $902.54 \pm 30.49$ & $919.67 \pm 30.39$ \\
BW 5 weeks & $1101.42 \pm 21.18$ & $1152.08 \pm 33.09$ & $1174.71 \pm 43.10$ \\
BW 6 weeks & $1422.53 \pm 24.75^{\mathrm{a}}$ & $1470.54 \pm 38.67^{\mathrm{a}}$ & $1551.46 \pm 47.00^{\mathrm{b}}$ \\
BW 7 weeks & $1763.57 \pm 29.00^{\mathrm{a}}$ & $1821.85 \pm 39.52^{\mathrm{a}}$ & $1968.46 \pm 55.66^{\mathrm{B}}$ \\
BW 8 weeks & $1895.26 \pm 28.31^{\mathrm{a}}$ & $1936.85 \pm 48.55^{\mathrm{a}}$ & $2097.88 \pm 50.41^{\mathrm{B}}$ \\
BW 9 weeks & $2076.68 \pm 34.14^{\mathrm{a}}$ & $2095.39 \pm 48.50^{\mathrm{b}}$ & $2340.50 \pm 51.51^{\mathrm{B}}$ \\
BW 10 weeks & $2247.40 \pm 41.56^{\mathrm{a}}$ & $2303.00 \pm 60.98^{\mathrm{a}}$ & $2510.88 \pm 56.21^{\mathrm{B}}$ \\
CY (\%) & $90.71 \pm 0.43$ & $91.55 \pm 1.36$ & $89.83 \pm 0.55$ \\
ECY (\%) & $74.56 \pm 0.34$ & $75.41 \pm 1.03$ & $74.11 \pm 0.44$ \\
AFP (\%) & $2.17 \pm 0.08^{\text {ab }}$ & $2.35 \pm 0.16^{\mathrm{b}}$ & $1.88 \pm 0.13^{\mathrm{a}}$ \\
\hline
\end{tabular}

The data are expressed as least square means \pm standard errors (mean $\pm \mathrm{SE}$ )

Only significant associations are shown in this table. Values within a row without a common lowercase and uppercase superscript are significantly different at $p<0.05$ and $p<.0 .01$, respectively. $\mathrm{CY}=$ carcass yield, $\mathrm{ECY}=$ Eviscerated carcass yield, $\mathrm{AFP}=$ abdominal fat percentage 
VLDLR may be used as a candidate gene for abdominal fat. We propose that there is a strong linkage existing in the polymorphisms of two regions. Additionally, some polymorphisms in the VLDLR gene were found to be associated with cerebellar ataxia and short stature, disease caused by mutations (Boycott et al., 2009; Schlotawa et al., 2013).

Signal peptides, as short peptides in $\mathrm{N}$-terminus of proteins, direct the proteins from their ribosomal assembly site to extracellular sites or to a particular cellular location. In this study, the amplified fragments was $374 \mathrm{bp}$, containing the $5^{\prime}$-UTR 243bp and $131 \mathrm{bp}$ region of the signal peptide, which encoded 37 amino acids of the signal peptide region. The genotype of -18bp/-18bp lacked 6 amino acids (Pro-Arg-Cys-GlyAla-Phe) compared with the $+18 \mathrm{bp} /+18 \mathrm{bp}$ genotype. It was assumed that this effect may be caused by change of VLDLR synthesis and positioning.

In conclusion, we found one SNP with 2 alleles $(+18 \mathrm{bp}$ and $-18 \mathrm{bp})$ in the signal peptide of the VLDLR gene. The frequency of $+18 \mathrm{bp}$ allele was higher than that of -18bp allele in the Gaoyou duck breed. The SNP was highly related with growth traits and abdominal fat percentage. Thus, this VLDLR SNP may potentially be used in marker assisted selection for growth rate and fat deposition traits in Gaoyou ducks. This novel SNP was closely related to the QTL affecting body weight and fat deposition traits. However, further investigations with different and larger duck populations are desired to determine how the VLDLR gene affects body weight and fat deposition traits.

\section{ACKNOWLEDGEMENTS}

This research was supported by the Priority Academic Program Development of Jiangsu Higher Education Institutions and Jiangsu Co-innovation Center for Prevention and Control of Important Animal Infectious Diseases and Zoonoses, Yangzhou, 225009. Postgraduate Degree innovation projects, Jiangsu Province (SJLX15_0677). Students' Academic and Scientific Innovation Fund funded project, Yangzhou University (X2015713)

\section{REFERENCES}

Boycott KM, Bonnemann C, Herz J, Neuert S, Beaulieu C, Scott JN, et al. Mutations in VLDLR as a cause for autosomal recessive cerebellar ataxia with mental retardation (Dysequilibrium Syndrome). Journal of Child Neurology 2009;24(10):1310-1315.

Boycott KM, Flavelle S, Bureau A, Glass HC, Fujiwara TM, Wirrell E, et al. Homozygous deletion of the very low density lipoprotein receptor gene causes autosomal recessive cerebellar hypoplasia with cerebral gyral simplification. American Journal of Human Genetcis 2005;77:477-483.
Brockmann GA, Haley CS, Renne U, Knott SA, Schwerin M. Quantitative trait loci affecting body weight and fatness from a mouse line selected for extreme high growth. Genetics 1998;150:369-381.

Clemente-Postigo M, Queipo-Ortuno MI, Fernandez-Garcia D, GomezHuelgas R, Tinahones FJ. Adipose tissue gene expression of factors related to lipid processing in obesity. PLoS ONE 2011; 6:e24783.

Crawford DC, Nord AS, Badzioch MD, Ranchalis J, McKinstry LA, Ahearn M, et al. A common VLDLR polymorphism interacts with APOE genotype in the prediction of carotid artery disease risk. Journal of Lipid Research 2008;49:588-596

Frykman PK, Brown MS, Yamamoto T, Goldstein JL, Herz, J. Normal plasma lipoproteins and fertility in gene-targeted mice homozygous for a disruption in the gene encoding very low density lipo-protein receptor. Proceedings of the National Academy Science USA 1995;92:84538457

Goliasova E, Wolf J. Impact of the ESR gene on litter size and production traits in Czech Large White pigs. Animal Genetcis 2004;35:293-297

Goudriaan JR, Tacken PJ, Dahlmans VE, Gijbels MJ, van Dijk KW, Havekes LM, et al. Protection from obesity in mice lacking the VLDL receptor. Arteriosclerosis, Thrombosis and Vascular Biology 2001;21,1488-1493.

Ismoyowati, Purwantini D. An estimation of genetic variation in Indonesian local duck using microsatellite marker. Asian Journal Poultry Science 2010;4(4):198-204.

Kim OY, Lee SM, Chung JH, Do HJ, Moon J, Shin MJ. Arginase I and the very low-density lipoprotein receptor are associated with phenotypic biomarkers for obesity. Nutrition 2012;28(6):635-639.

Kunej T, Jevsinek Skok D, Zorc M, Ogrinc A, Michal JJ, Kovac M, et al Obesity gene atlas in mammals. Journal of Genomics 2012;1:45-55.

Lotfi E, Zerehdaran S, Azari AM. Genetic evaluation of carcass composition and fat deposition in Japanese quail. Poultry Science 2011;90:22022208.

Nimpf J, Schneider WJ. The VLDL receptor: an LDL receptor relative with eight ligand binding repeats, LR8. Atherosclerosis 1998;141(2):191202

Nimpf J, Schneider WJ. From cholesterol transport to signal transduction: low density lipoprotein receptor, very low density lipoprotein receptor, and apolipoprotein E receptor-2. Biochimica et Biophysica Acta 2000:1529(1/3):287-298.

NRC - National Research Council. Nutrient requirements of poultry. $9^{\text {th }}$ ed Washington: National Academy Press; 1994.

Reddy SS, Connor TE, Weeber EJ, Rebeck W. Similarities and differences in structure, expression, and functions of $V L D L R$ and ApoER2. Molecular Neurodegeneration 2011;6(1): 30.

Schlotawa L, Hotz A, Zeschnigk C, Hartmann B, Gärtner J, Morris-Rosendahl D. Cerebellar ataxia, mental retardation and dysequilibrium syndrome 1 CAMRQ1) caused by an unusual constellation of VLDLR mutation. Journal of Neurology 2013;260(6):1678-1680

Takahashi S, Suzuki J, Kohno M, Oida K, Tamai T, Miyabo S, et al. Enhancement of the binding of tri-glyceride-rich lipoproteins to the very low density lipoprotein receptor by apolipoprotein E and lipoprotein lipase. Journal of Biological Chemistry 1995;270: 15747-15754.

Tao H, Aakula S, Abumrad NN, Hajri T. Peroxisome proliferator-activated receptor- regulates the expression and function of very-low density lipoprotein receptor. American Journal of Physiology- Endocrinology and Metabolism 2010;298:E68-E79

Wang C, Li SJ, Yu WH, Xin QW, Li C, Feng YP, et al. Cloning and Expression Profiling of the VLDLR Gene Associated with Egg Performance in Duck (Anas Platyrhynchos). Genetics Selection Evolution 2011;43:29. 
Ming-liang C, Cong W, Xuan D,

Lu L, Tang-jie Z
A Novel Polymorphism of VLDLR Signal Peptide Coding Region and Its Association with Growth and Abdominal Fat Traits of Gaoyou Domestic Ducks
Wu Y, Pan AL, Pi JS, Pu YJ, Du JP, Liang ZH, et al. One novel SNP of growth hormone gene and its associations with growth and carcass traits in ducks. Molecular Biology Reports 2012;39(8):8027-8033.

Yagyu H, Lutz EP, Kako Y, Marks S, Hu Y, Choi SY, et al. Very low density lipoprotein (VLDL) receptor-deficientmice have reduced lipoprotein lipase activity. Possible causes of hypertriglyceridemia and reduced body mass with VLDL receptor deficiency. Journal of Biological Chemistry 2002;277:10037-10043.
Zerehdaran S, Vereijken AL, Van Arendonk JA, Van der Waaijt EH. Estimation of genetic parameters for fat deposition and carcass traits in broilers. Poultry Science 2004;83:521-525.

Zhao NN, Lin S, Wang ZQ, Zhang TJ. VLDLR gene polymorphism associated with abdominal fat in Gaoyou domestic duck breed. Czech Journal of Animal Science 2015;60:178-184. 